\title{
Changes in the phosphorylation of nucleotide metabolism-associated proteins by leukemia inhibitory factor in mouse embryonic stem cells
}

\author{
HWA-RYUNG SONG ${ }^{1 *}$, HAN-KYU KIM ${ }^{1 *}$, SEUNG-GOOK KIM ${ }^{1}$, HYUNG-JIN LIM ${ }^{1}$, \\ HYUN-YI KIM ${ }^{2}$ and MYUNG-KWAN HAN ${ }^{1}$ \\ ${ }^{1}$ Department of Microbiology, Jeonbuk National University Medical School, Jeonju, Jeollabuk 54896; \\ ${ }^{2}$ Division of Anatomy and Developmental Biology, Department of Oral Biology, \\ Yonsei University College of Dentistry, Seoul 03722, Republic of Korea
}

Received March 19, 2020; Accepted September 22, 2020

DOI: $10.3892 / \mathrm{mmr} .2021 .12070$

\begin{abstract}
Leukemia inhibitory factor (LIF) is a stem cell growth factor that maintains self-renewal of mouse embryonic stem cells (mESCs). LIF is a cytokine in the interleukin-6 family and signals via the common receptor subunit gp130 and ligand-specific LIF receptor. LIF causes heterodimerization of the LIF receptor and gp130, activating the Janus kinase/STAT and MAPK pathways, resulting in changes in protein phosphorylation. The present study profiled LIF-mediated protein phosphorylation changes in mESCs via proteomic analysis. mESCs treated in the presence or absence of LIF were analyzed via two-dimensional differential in-gel electrophoresis and protein and phosphoprotein staining. Protein identification was performed by matrix-assisted laser desorption/ionization-time of flight mass spectrophotometry. Increased phosphorylation of 16 proteins and decreased phosphorylation of 34 proteins in response to LIF treatment was detected. Gene Ontology terms enriched in these proteins included 'organonitrogen compound metabolic process', 'regulation of mRNA splicing via spliceosome' and 'nucleotide metabolic process'. The present results revealed that LIF modulated phosphorylation levels of nucleotide metabolism-associated proteins, thus providing insight into the mechanism underlying LIF action in mESCs.
\end{abstract}

\section{Introduction}

Embryonic stem cells (ESCs) can be derived from the inner cell mass from mouse (1) or human (2) embryos. ESCs

Correspondence to: Professor Myung-Kwan Han, Department of Microbiology, Jeonbuk National University Medical School, 567 Baekje-daero, Deokjin, Jeonju, Jeollabuk 54896, Republic of Korea E-mail: iamtom@chonbuk.ac.kr

*Contributed equally

Key words: embryonic stem cells, leukemia inhibitory factor, phosphorylation, mouse have unlimited potential for self-renewal and pluripotency, allowing for their differentiation into all types of cell (3). ESC self-renewal can be maintained by leukemia inhibitory factor (LIF) in mouse (m)ESCs and by basic fibroblast growth factor in human ESCs $(1,2)$. Induced pluripotent stem cells (iPSCs) can be derived from somatic cells by transducing them with a set of reprogramming factors, such as Oct3/4, Sox2, c-Myc, Kruppel like factor 4, lin-28 homolog A and Nanog $(4,5)$, and can be used in patient-specific regenerative medicine. However, under commonly used culture conditions, involving leukemia inhibitory factor plus fetal bovine serum, for in vitro expansion, iPSCs tend to spontaneously differentiate (6). It is necessary to understand the molecular mechanisms of ESC self-renewal to establish efficient in vitro expansion systems for stem cell therapy.

LIF, an interleukin- 6 family cytokine, binds to a heterodimeric receptor consisting of the low-affinity LIF receptor and gp130 (7). LIF receptor-gp130 dimerization leads to Janus kinase (JAK) activation and signal STAT phosphorylation (8). JAKs also stimulate phosphatidylinositol 3-kinase by phosphorylating its regulatory subunit $\mathrm{p} 85$, thereby activating AKT serine/threonine kinase 1 (9), to inhibit its major target protein glycogen synthetase kinase $3 \beta$, resulting in increased levels of Nanog homeobox and Myc proto-oncogene, a basic helix-loop-helix transcription factor, which are important regulators of mESC self-renewal (10). JAKs also phosphorylate protein tyrosine phosphatase non-receptor type 11, which then interacts with the growth factor receptor-bound protein 2-SOS Ras/Rac guanine nucleotide exchange factor 1 complex to activate the MAPK pathway (11). This indicates that LIF induces the phosphorylation of numerous proteins by regulating a number of protein kinases and phosphatases. Thus, LIF-mediated phosphorylation/dephosphorylation profiling in mESCs may be helpful for understanding the molecular mechanisms underlying their self-renewal.

In order to identify proteins that are phosphorylated/dephosphorylated following LIF treatment of mESCs, two-dimensional (2-D) differential in-gel electrophoresis (DIGE), phosphostaining, and protein identification by mass spectrometry (MS) were performed in the present 
study. The present study aimed to compare phosphorylation in LIF-deprived and LIF-treated mESCs, and to identify LIF-mediated phosphorylated or dephosphorylated proteins.

\section{Materials and methods}

Cell culture and treatment. The mESC cell line ES-R1 (Sigma-Aldrich; Merck KGaA) was maintained on $0.2 \%$ gelatin-coated plates in DMEM supplemented with $15 \%$ fetal bovine serum and $1 \%$ GlutaMAX, $1 \%$ non-essential amino acids, antibiotics, $100 \mu \mathrm{M}$ 2-mercaptoethanol and 1,000 U/ml recombinant LIF (all purchased from Gibco; Thermo Fisher Scientific, Inc.).

Western blotting. Following 24-h culture in the absence of LIF, mESCs were washed with PBS three times and treated with PBS or 1,000 U/ml LIF (in DMEM supplemented with 1\% GlutaMAX and $1 \%$ non-essential amino acids) for different durations at $37^{\circ} \mathrm{C}$. Total protein was extracted from cells using M-PER mammalian protein extraction reagent (Pierce; Thermo Fisher Scientific, Inc.) supplemented with a protease inhibitor cocktail (cOmplete ${ }^{\mathrm{TM}}$; Roche Diagnostics) and a phosphatase inhibitor cocktail (PhosSTOP ${ }^{\mathrm{TM}}$; Roche Diagnostics) on ice for $1 \mathrm{~h}$. Total protein was quantified by the Bradford's method using Protein Assay Dye Reagent Concentrate (Bio-Rad Laboratories, Inc.). Following centrifugation at $10,000 \mathrm{xg}$ for $10 \mathrm{~min}$ at $37^{\circ} \mathrm{C}$, proteins (20 $\mu \mathrm{g}$ /lane) were separated via 9\% SDS-PAGE and transferred to PVDF membranes. The blots were incubated overnight at $4^{\circ} \mathrm{C}$ with the following primary antibodies: Anti-phosphoserine (cat. no. AB1603; 1:5,000; Chemicon International; Thermo Fisher Scientific, Inc.), anti-phosphothreonine (cat. no. sc-5267; 1:200; Santa Cruz Biotechnology, Inc.), anti-phosphotyrosine (cat. no. 05-321; 1:5,000; EMD Millipore), anti-HSP90 $\alpha$ (cat. no. PA5-16341; 1:2,000; Invitrogen; Thermo Fisher Scientific, Inc.), anti-phospho-HSP90 $\alpha$ (cat. no. 3488; 1:2,000; Cell Signaling Technology, Inc.) and anti- $\beta$-actin (cat, no. A5441; 1:5,000; Sigma-Aldrich; Merck KGaA). Following primary incubation, the membranes were incubated for $40 \mathrm{~min}$ at room temperature with goat anti-mouse (cat. no. sc-2005; 1:1,000; Santa Cruz Biotechnology, Inc.) or anti-rabbit (cat. no. A16035; 1:4,000; Thermo Fisher Scientific, Inc.) alkaline phosphatase-conjugated secondary antibodies. Protein bands were visualized using an ECL system (Intron Biotechnology, Inc.) and a Fusion Fx7 Spectra (Vilber Lourmat). Protein expression was quantified using Fusion-Capt software (version 16.08; Vilber Lourmat).

Preparation of samples for 2-D DIGE. Nagy R1 mESC pellets $(10 \mathrm{mg})$ were suspended in $200 \mu \mathrm{l} 2$-D cell lysis buffer [30 mM Tris- $\mathrm{HCl}(\mathrm{pH} 8.8), 7 \mathrm{M}$ urea, $2 \mathrm{M}$ thiourea and $4 \%$ 3-[(3-cholamidopropyl)dimethylammonio]-1-propanesulfonate (CHAPS)], sonicated at $4^{\circ} \mathrm{C}$ for $3 \times 30 \mathrm{sec}$ between a 2 min interval and agitated for $30 \mathrm{~min}$ at room temperature. The samples were then centrifuged at $4^{\circ} \mathrm{C}$ for $30 \mathrm{~min}$ at $14,000 \mathrm{x} \mathrm{g}$ and the supernatants were collected. Protein concentrations were measured using a protein assay kit (cat. no. 5000001, Bio-Rad Laboratories, Inc.).

Protein staining with CyDye. For protein staining, $30 \mu \mathrm{g}$ mESC lysate was labeled with CyDye on ice in the dark for $30 \mathrm{~min}$. The reaction was stopped by adding $1 \mu 110 \mathrm{mM}$ lysine and incubating the lysates on ice in the dark for an additional $15 \mathrm{~min}$. Next, 2-D sample buffer [8 M urea, 4\% CHAPS, $20 \mathrm{mg} / \mathrm{ml}$ dithiothreitol (DTT), 2\% Pharmalytes (Sigma-Aldrich; Merck KGaA) and trace amount of bromophenol blue], $100 \mu$ l destreak solution and rehydration buffer (7 M urea, $2 \mathrm{M}$ thiourea, 4\% CHAPS, $20 \mathrm{mg} / \mathrm{ml}$ DTT, $1 \%$ pharmalytes and trace amount of bromophenol blue) were added to the labeling mixture to a total volume of $250 \mu \mathrm{l}$.

Isoelectric focusing and SDS-PAGE. Isoelectric focusing (linear; pH 3-10) was performed according to the protocol provided by Amersham (Cytiva). Immobilized $\mathrm{pH}$ gradient strips were incubated at $15^{\circ} \mathrm{C}$ in equilibration buffer $1[50 \mathrm{mM}$ Tris- $\mathrm{HCl}$ (pH 8.8), $6 \mathrm{M}$ urea, $30 \%$ glycerol, $2 \%$ SDS, trace amount of bromophenol blue and $10 \mathrm{mg} / \mathrm{ml}$ DTT] for $15 \mathrm{~min}$ with gentle shaking. The strips were rinsed in equilibration buffer 2 [50 mM Tris-HCl (pH 8.8), $6 \mathrm{M}$ urea, 30\% glycerol, $2 \%$ SDS, trace amount of bromophenol blue and $45 \mathrm{mg} / \mathrm{ml}$ DTT] for 10 min with gentle shaking. The immobilized $\mathrm{pH}$ gradient strips were loaded onto $12 \%$ SDS-PAGE gels, which were run at $15^{\circ} \mathrm{C}$ until the dye front ran out from the gels.

Phosphostaining, imaging and data analysis. The gels were scanned immediately following SDS-PAGE on a Typhoon TRIO variable-mode imager (Amersham; Cytiva). The gels were then stained with Pro-Q Diamond Phosphoprotein Gel Stain (Invitrogen; Thermo Fisher Scientific, Inc.) following the manufacturer's protocol, followed by scanning on the Typhoon TRIO and analysis using DeCyder version 6.0 (Cytiva). All circled spots in DeCyder were located manually and the pixel count (maximum volume) of each spot was exported. Then, phosphorylation ratios between LIF-starved and -treated samples were calculated. Statistical significance was calculated using DeCyder software (Cytiva). Only proteins with $\geq 2$-fold difference in protein phosphorylation, $100 \%$ presence in all gel images and $\mathrm{P}<0.05$ (determined via ANOVA) were selected for further analysis.

Spot picking and trypsin digestion. Spots of interest were picked by an Ettan Spot Picker (Amersham; Cytiva) based on the 2-D DIGE and spot picking design generated via DeCyder. Proteins were digested in-gel with modified porcine trypsin protease (Trypsin Gold; Promega Corporation) and desalted on C18 ZipTips (EMD Millipore). Peptides were eluted from ZipTips with $0.5 \mu 1$ matrix solution [ $\alpha$-cyano-4-hydroxycinnamic acid $(5 \mathrm{mg} / \mathrm{ml})$ ] in $50 \%$ acetonitrile, $0.1 \%$ trifluoroacetic acid and $25 \mathrm{mM}$ ammonium bicarbonate, then spotted onto a matrix-assisted laser desorption/ionization (MALDI) plate (ABI 01-192-6-AB; Applied Biosystems; Thermo Fisher Scientific, Inc.).

MS. MALDI-time-of-flight (TOF) MS and TOF/TOF tandem MS/MS were performed on an AB SCIEX TOF/TOF 5800 System (AB Sciex LLC). MALDI-TOF mass spectra were acquired in reflectron-positive ion mode, averaging 4,000 laser shots per spectrum. TOF/TOF tandem MS fragmentation spectra were acquired for each sample, averaging 4,000 laser shots per fragmentation spectrum on the ten most abundant ions present in each sample (excluding tryptic peptides and other known background ions). 


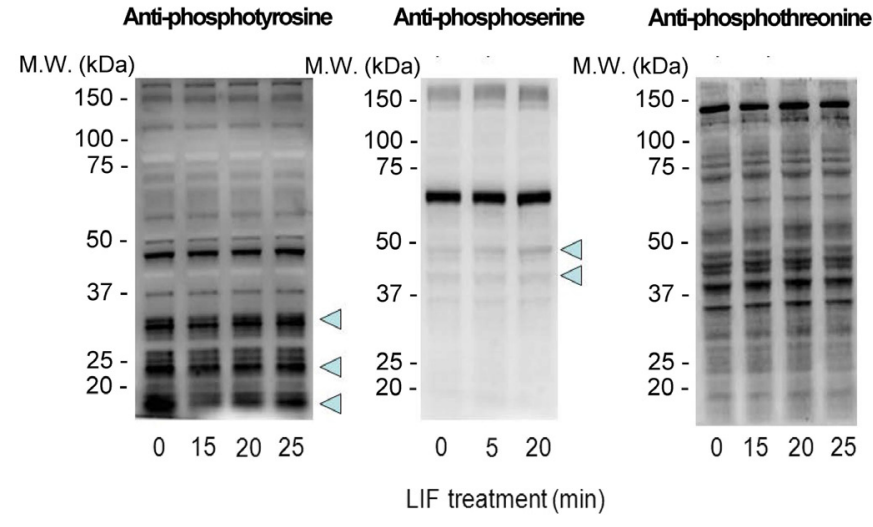

Figure 1. Tyrosine, serine and threonine phosphorylation changes in LIF-stimulated mESCs. Following 24-h culture in the absence of LIF, mESCs were treated with LIF for the indicated time-points and analyzed by western blotting with phosphotyrosine, phosphoserine and phosphothreonine antibodies. Arrows indicate increased intensity of representative protein bands. LIF, leukemia inhibitory factor; mESC, mouse embryonic stem cell.

Database searches. Both the resulting peptide masses and associated fragmentation spectra were submitted to a GPS Explorer workstation equipped with the Mascot search engine (Matrix Science, Inc.) to search the non-redundant database of the National Center for Biotechnology Information (www.ncbi.nlm. nih.gov/refseq). Searches were performed without constraining protein molecular weights or isoelectric points, with variable carbamidomethylation of cysteine and oxidation of methionine residues, and permitting one missed cleavage. Candidates with either a protein score or ion confidence interval $>95$ were considered to be significant. The list of significantly regulated phosphoproteins was subjected to Gene Ontology (GO) analysis in the Database for Annotation, Visualization and Integrated Discovery (DAVID) using DAVID Web Service 1.22.0, a $\mathrm{R}$ package for retrieving data from DAVID (12). The retrieved data were visualized using GOplot 1.0.2 (13) in rstudio 1.2.1335-1 and the NaviGO (14) webpage (kiharalab.org/web/navigo).

\section{Results}

LIF induces tyrosine, serine, and threonine phosphorylation in $\mathrm{mESCS}$. Previous studies have demonstrated that the optimal concentration of LIF to be added to culture media is $1,000 \mathrm{U} / \mathrm{ml}$, regardless of the presence or absence of feeder cells $(3,15,16)$. Typically, $1,000 \mathrm{U} / \mathrm{ml} \mathrm{LIF}$ is used in culture to maintain the undifferentiated state of mESCs. In order to deprive mESCs of LIF, addition of an LIF-specific inhibitor would be ideal. However, specific inhibitors for LIF are not currently available. In the present study, mESCs cultured in the presence of $1,000 \mathrm{U} / \mathrm{ml} \mathrm{LIF}$ for $24 \mathrm{~h}$ were washed with PBS three times and then retreated with $1,000 \mathrm{U} / \mathrm{ml} \mathrm{LIF}$ for different durations to assess the effects of LIF on mESC phosphorylation patterns. Protein phosphorylation was analyzed by western blotting using antibodies against phosphoserine, phosphothreonine and phosphotyrosine. Rapid changes in serine and tyrosine phosphorylation were observed compared with threonine phosphorylation (Fig. 1).

Analysis of differentially phosphorylated proteins in $L I F$-treated mESCs via 2-D DIGE. In the present study,

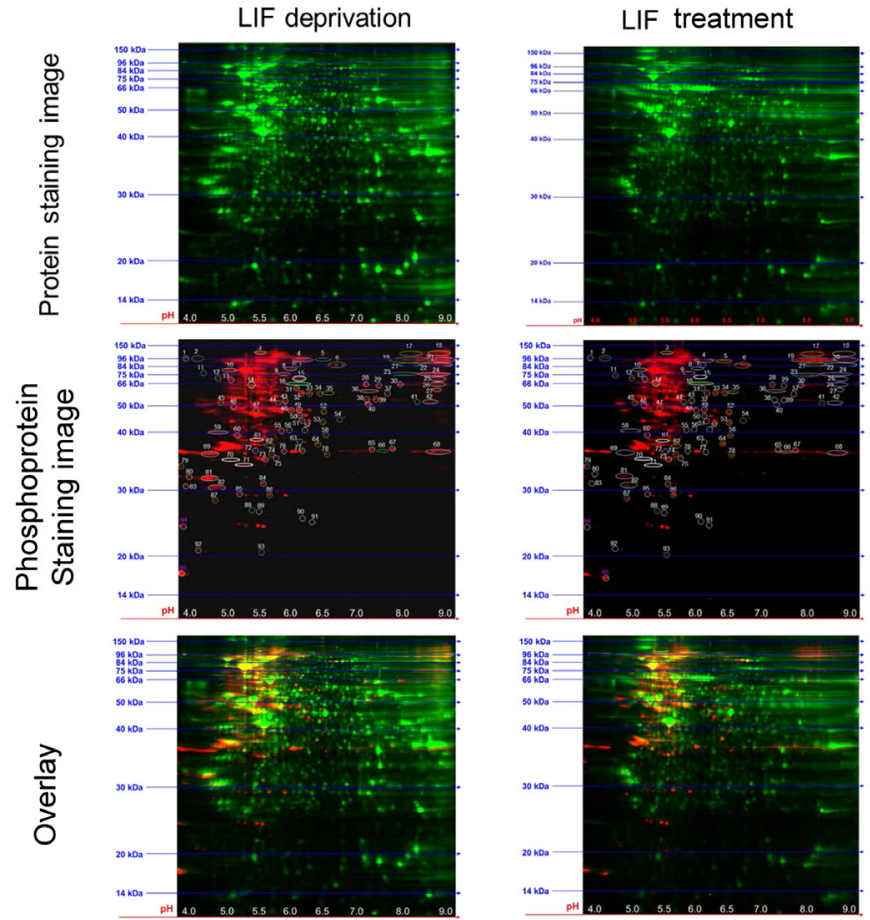

Figure 2. Analysis via 2-D DIGE followed by phosphoprotein staining. Following 24-h culture in the absence of LIF, mouse embryonic stem cells were treated with LIF for $20 \mathrm{~min}$. Protein extracts from cells before and after LIF treatment were labeled with CyDye and 2-D DIGE ( $\mathrm{pH} 3-10)$ was performed. Total proteins are presented in green; phosphoproteins are presented in red. In total, 95 spots were selected for identification. 2-D DIGE, two-dimensional differential in-gel electrophoresis; LIF, leukemia inhibitory factor.

2-D DIGE was performed, followed by total protein and phosphoprotein staining to analyze LIF-induced protein phosphorylation changes in mESCs (Fig. 2). Gels containing resolved CyDye-labeled protein extracts from LIF-starved and -treated mESCs were scanned and then stained with phosphospecific Pro-Q Diamond stain. Phosphoproteins were detected as spots with increased fluorescence intensity (CyDye + Pro-Q) compared with CyDye alone. Spot quantification identified 95 spots with altered intensity between LIF-starved and -treated mESCs. Normalized Pro-Q Diamond intensity ratios for each spot between LIF-starved and -treated samples are listed in Table I.

Identification of differentially phosphorylated proteins in LIF-treated mESCs. A total of 51 spots whose phosphorylation/dephosphorylation levels were significantly changed ( $>2$-fold; Table II) were selected for identification via MALDI-TOF MS analysis. Proteins whose phosphorylation levels were significantly increased and decreased following LIF treatment are listed in Tables II and III, respectively. Among the proteins with altered phosphorylation levels following LIF treatment, some were functionally associated mESC stemness and differentiation, such as HSP7C, HS90A, NPM and SRSF1 (3,17-19). In order to validate LIF-dependent phosphorylation, western blot analysis was performed using an anti-phospho-HSP90 $\alpha$ (Thr5/7) antibody. HSP90 $\alpha$ phosphorylation was significantly decreased by LIF treatment (Fig. 3).

There were four spots for NUCL in the 2-D electrophoresis gel with two molecular weights (77 and $88 \mathrm{kDa})$ and two 

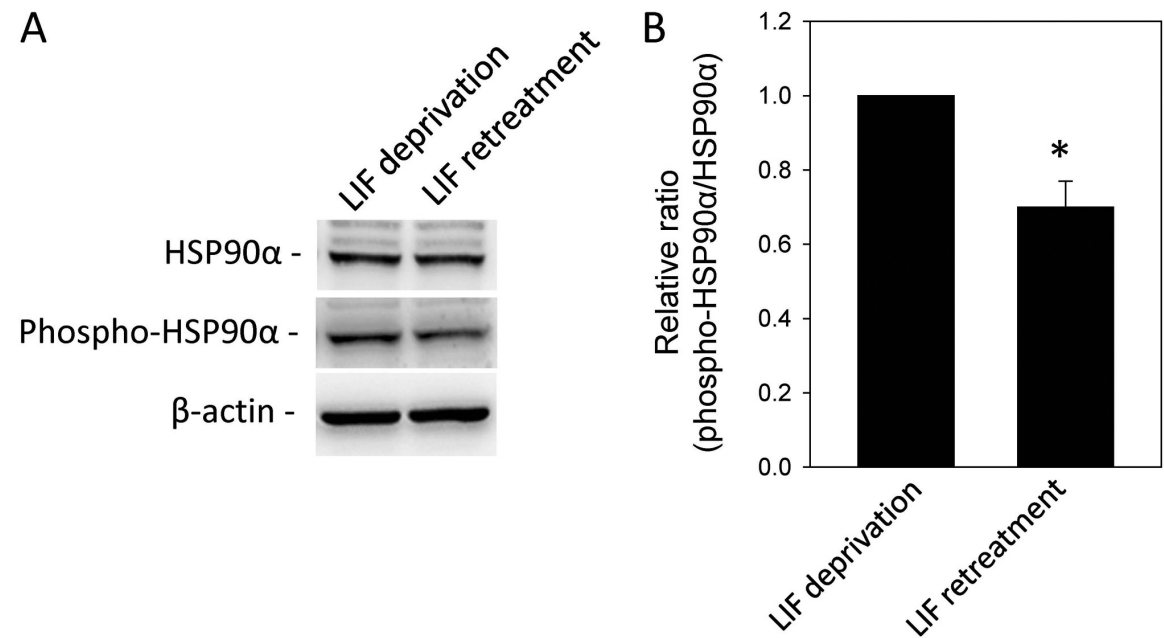

Figure 3. Threonine (Thr5/7) phosphorylation of HSP90 $\alpha$ decreases in LIF-stimulated mESCs. (A) Following 24-h culture in the absence of LIF, mESCs were treated with vehicle or LIF for $20 \mathrm{~min}$ and analyzed by western blotting with antibodies for phosphorylated-HSP90 $\alpha$ (Thr5/7), HSP90 $\alpha$ and $\beta$-actin. (B) Densitometric analysis. Data are presented as the mean \pm SEM of three experiments. "P<0.01 vs. LIF deprivation. LIF, leukemia inhibitory factor; mESC, mouse embryonic stem cells.
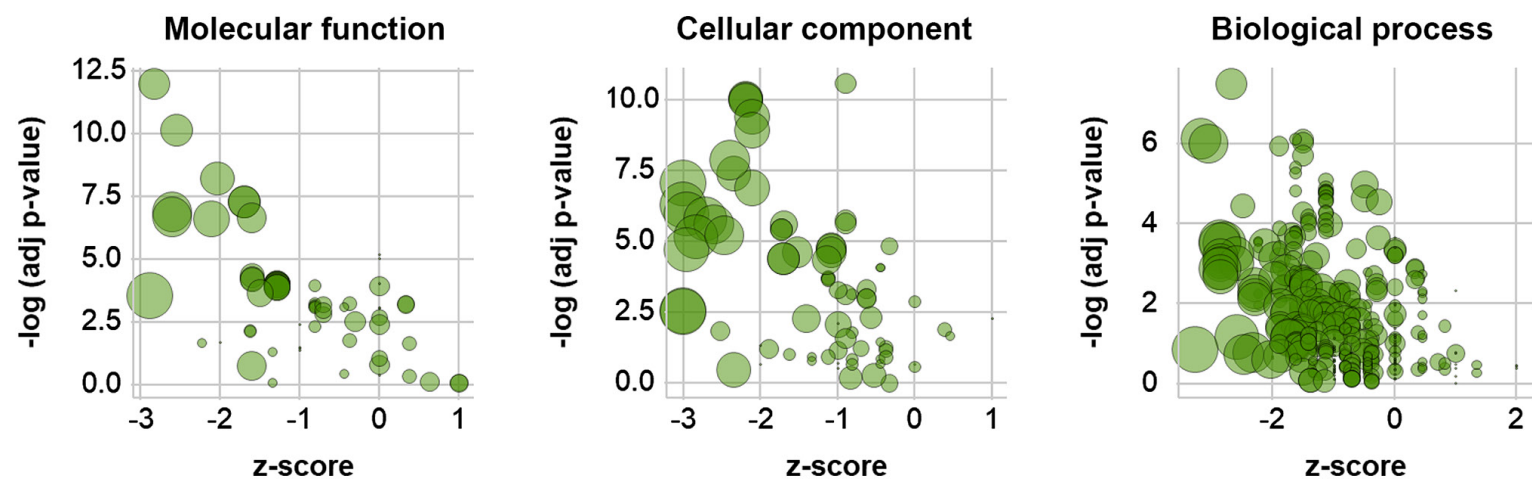

Figure 4. Overview of the enriched GO terms of identified phosphoproteins. A bubble plot for overview of the enriched GO terms of phosphoproteins produced and visualized using Database for Annotation, Visualization and Integrated Discovery and GOplot R package. Bubbles represent GO terms; bubble size of indicates number of proteins. Z-scores were calculated based on the fold-change of phosphorylation of member proteins. GO, Gene Ontology.

different PI values (8.7 and 8.9). The phosphorylation of two spots (spot nos. 23 and 19) was increased and that of the other two (spot nos. 20 and 24) was decreased by LIF stimulation.

GO analysis of differentially phosphorylated genes in LIF-treated mESCs. GO enrichment analysis was performed to functionally annotate differentially phosphorylated proteins following LIF treatment. Functional annotation clustering identified significantly enriched GO terms and protein members. The z-scores of GO terms were calculated based on the fold-change of phosphorylation values of their members (Fig. 4). The majority of highly significant GO terms had negative $\mathrm{z}$-scores, indicating that LIF treatment induced dephosphorylation of member proteins (Fig. 4); consistently, the $\mathrm{z}$-scores of the top ten GO terms by significance in each category were $<0$ (Table IV). In order to visualize the hierarchy of associations between the top ten terms in each category, a GO term network was generated (Fig. 5). Terms such as 'poly(A) RNA binding' (GO:0044822) and 'nucleotide binding' (GO:0000166), 'nucleus' (GO:0005634) and 'extracellular exosome' (GO:0070062), and 'regulation of mRNA splicing via the spliceosome' (GO:0048024) were found at the base of the molecular function, cellular component and biological process networks, respectively. In order to investigate individual proteins, associations between $\mathrm{GO}$ terms and the phosphorylation ratios of individual member proteins were visualized as a heatmap (Fig. 6). The heat shock proteins HSP7C and HS90A, which are found in a transcription factor complex binding Oct4 promoter in iPSCs (20), were phosphorylated by LIF treatment and were associated with the largest number of enriched terms. nucleophosmin (NPM), phosphatidylethanolamine-binding protein 1 (PEBP1), and serine-arginine-rich splicing factor 3 (SRSF3) were highly dephosphorylated by LIF treatment and were associated with the majority of the enriched terms, as well as with stem cell and progenitor cell regulation (21-23).

\section{Discussion}

The present study demonstrated that LIF increased tyrosine and serine phosphorylation of numerous mESC proteins. Total phosphorylation levels of a number of proteins following LIF treatment were analyzed; 15 proteins were phosphorylated and 33 were dephosphorylated. The most significantly 
Table I. Normalized phosphorylation ratio of protein spots between LIF-deprived and -treated mouse embryonic stem cells.

Spot LIF deprivation LIF treatment LIF treatment/

no. Max volume Max volume deprivation ratio

\begin{tabular}{|c|c|c|c|c|c|c|c|}
\hline \multicolumn{4}{|c|}{ Detween Lir-deprived and -treded mouse emoryonic stem } & \multirow{2}{*}{\multicolumn{2}{|c|}{$\begin{array}{l}\text { Spot } \\
\text { no. }\end{array}$}} & \multirow[b]{2}{*}{$\begin{array}{l}\text { LIF treatment } \\
\text { Max volume }\end{array}$} & \multirow[b]{2}{*}{$\begin{array}{c}\text { LIF treatment/ } \\
\text { deprivation ratio }\end{array}$} \\
\hline cells. & & & & & & & \\
\hline $\begin{array}{l}\text { Spot } \\
\text { no. }\end{array}$ & $\begin{array}{l}\text { LIF deprivation } \\
\text { Max volume }\end{array}$ & $\begin{array}{l}\text { LIF treatment } \\
\text { Max volume }\end{array}$ & $\begin{array}{l}\text { LIF treatment/ } \\
\text { deprivation ratio }\end{array}$ & 49 & $1.25 \times 10^{6}$ & $5.68 \times 10^{5}$ & 0.5 \\
\hline & & & & 50 & $4.88 \times 10^{5}$ & $3.29 \times 10^{5}$ & 0.7 \\
\hline 1 & $4.98 \times 10^{5}$ & $1.42 \times 10^{5}$ & 0.3 & 51 & $3.41 \times 10^{5}$ & $2.30 \times 10^{5}$ & 0.7 \\
\hline 2 & $7.13 \times 10^{4}$ & $6.28 \times 10^{5}$ & 8.8 & 52 & $5.30 \times 10^{5}$ & $7.71 \times 10^{5}$ & 1.5 \\
\hline 3 & $5.18 \times 10^{5}$ & $2.59 \times 10^{5}$ & 0.5 & 53 & $4.69 \times 10^{5}$ & $7.39 \times 10^{5}$ & 1.6 \\
\hline 4 & $1.55 \times 10^{6}$ & $1.02 \times 10^{6}$ & 0.7 & 54 & $8.30 \times 10^{4}$ & $1.57 \times 10^{5}$ & 1.9 \\
\hline 5 & $1.52 \times 10^{5}$ & $2.31 \times 10^{5}$ & 1.5 & 55 & $2.34 \times 10^{5}$ & $1.67 \times 10^{5}$ & 0.7 \\
\hline 6 & $1.51 \times 10^{6}$ & $2.74 \times 10^{6}$ & 1.8 & 56 & $1.17 \times 10^{5}$ & $4.23 \times 10^{4}$ & 0.4 \\
\hline 7 & $1.90 \times 10^{5}$ & $2.65 \times 10^{4}$ & 0.1 & 57 & $6.96 \times 10^{4}$ & $4.48 \times 10^{4}$ & 0.6 \\
\hline 8 & $2.17 \times 10^{5}$ & $5.27 \times 10^{4}$ & 0.2 & 58 & $2.95 \times 10^{5}$ & $6.30 \times 10^{5}$ & 2.1 \\
\hline 9 & $2.53 \times 10^{5}$ & $1.43 \times 10^{5}$ & 0.6 & 59 & $1.22 \times 10^{6}$ & $4.21 \times 10^{5}$ & 0.3 \\
\hline 10 & $9.69 \times 10^{5}$ & $4.64 \times 10^{5}$ & 0.5 & 60 & $3.99 \times 10^{5}$ & $1.99 \times 10^{5}$ & 0.5 \\
\hline 11 & $1.80 \times 10^{5}$ & $4.37 \times 10^{5}$ & 2.4 & 61 & $3.31 \times 10^{5}$ & $2.33 \times 10^{5}$ & 0.7 \\
\hline 12 & $1.96 \times 10^{5}$ & $6.56 \times 10^{5}$ & 3.3 & 62 & $2.36 \times 10^{5}$ & $4.53 \times 10^{5}$ & 1.9 \\
\hline 13 & $4.55 \times 10^{5}$ & $2.77 \times 10^{5}$ & 0.6 & 63 & $1.08 \times 10^{5}$ & $8.63 \times 10^{4}$ & 0.8 \\
\hline 14 & $6.43 \times 10^{5}$ & $1.43 \times 10^{6}$ & 2.2 & 64 & $7.20 \times 10^{5}$ & $1.45 \times 10^{6}$ & 2.0 \\
\hline 15 & $6.59 \times 10^{5}$ & $3.26 \times 10^{5}$ & 0.5 & 65 & $6.50 \times 10^{5}$ & $1.50 \times 10^{5}$ & 0.2 \\
\hline 16 & $2.78 \times 10^{5}$ & $1.13 \times 10^{6}$ & 4.1 & 66 & $1.87 \times 10^{5}$ & $6.53 \times 10^{5}$ & 3.5 \\
\hline 17 & $3.12 \times 10^{5}$ & $6.90 \times 10^{5}$ & 2.2 & 67 & $9.35 \times 10^{5}$ & $5.74 \times 10^{5}$ & 0.6 \\
\hline 18 & $9.06 \times 10^{5}$ & $2.71 \times 10^{5}$ & 0.3 & 68 & $2.98 \times 10^{6}$ & $2.19 \times 10^{6}$ & 0.7 \\
\hline 19 & $2.07 \times 10^{6}$ & $6.04 \times 10^{6}$ & 2.9 & 69 & $3.76 \times 10^{6}$ & $4.02 \times 10^{5}$ & 0.1 \\
\hline 20 & $5.48 \times 10^{6}$ & $1.08 \times 10^{6}$ & 0.2 & 70 & $6.17 \times 10^{5}$ & $3.63 \times 10^{5}$ & 0.6 \\
\hline 21 & $4.13 \times 10^{5}$ & $8.07 \times 10^{5}$ & 2.0 & 71 & $6.89 \times 10^{5}$ & $3.89 \times 10^{5}$ & 0.6 \\
\hline 22 & $2.15 \times 10^{6}$ & $2.79 \times 10^{5}$ & 0.1 & 72 & $2.20 \times 10^{5}$ & $1.41 \times 10^{5}$ & 0.6 \\
\hline 23 & $4.44 \times 10^{5}$ & $1.58 \times 10^{6}$ & 3.6 & 73 & $9.00 \times 10^{5}$ & $6.58 \times 10^{5}$ & 0.7 \\
\hline 24 & $3.16 \times 10^{6}$ & $6.68 \times 10^{5}$ & 0.2 & 74 & $2.01 \times 10^{5}$ & $2.90 \times 10^{5}$ & 1.4 \\
\hline 25 & $2.20 \times 10^{5}$ & $5.81 \times 10^{4}$ & 0.3 & 75 & $4.30 \times 10^{5}$ & $3.80 \times 10^{5}$ & 0.9 \\
\hline 26 & $9.99 \times 10^{5}$ & $4.63 \times 10^{5}$ & 0.5 & 76 & $3.42 \times 10^{5}$ & $2.30 \times 10^{5}$ & 0.7 \\
\hline 27 & $2.95 \times 10^{5}$ & $7.09 \times 10^{4}$ & 0.2 & 77 & $8.22 \times 10^{5}$ & $2.37 \times 10^{5}$ & 0.3 \\
\hline 28 & $7.06 \times 10^{5}$ & $3.90 \times 10^{5}$ & 0.6 & 78 & $4.27 \times 10^{5}$ & $5.56 \times 10^{5}$ & 1.3 \\
\hline 29 & $5.49 \times 10^{5}$ & $2.82 \times 10^{5}$ & 0.5 & 79 & $1.12 \times 10^{5}$ & $4.59 \times 10^{5}$ & 4.1 \\
\hline 30 & $1.70 \times 10^{6}$ & $7.66 \times 10^{5}$ & 0.5 & 80 & $6.92 \times 10^{5}$ & $5.34 \times 10^{4}$ & 0.1 \\
\hline 31 & $7.28 \times 10^{5}$ & $3.05 \times 10^{5}$ & 0.4 & 81 & $2.58 \times 10^{6}$ & $9.17 \times 10^{5}$ & 0.4 \\
\hline 32 & $6.80 \times 10^{5}$ & $3.70 \times 10^{5}$ & 0.5 & 82 & $1.77 \times 10^{6}$ & $6.60 \times 10^{5}$ & 0.4 \\
\hline 33 & $5.45 \times 10^{5}$ & $6.39 \times 10^{5}$ & 1.2 & 83 & $6.56 \times 10^{5}$ & $4.39 \times 10^{4}$ & 0.1 \\
\hline 34 & $3.31 \times 10^{5}$ & $3.93 \times 10^{5}$ & 1.2 & 84 & $5.67 \times 10^{5}$ & $4.07 \times 10^{5}$ & 0.7 \\
\hline 35 & $9.89 \times 10^{4}$ & $6.95 \times 10^{5}$ & 7.0 & 85 & $3.69 \times 10^{5}$ & $3.21 \times 10^{5}$ & 0.9 \\
\hline 36 & $6.57 \times 10^{5}$ & $6.04 \times 10^{5}$ & 0.9 & 86 & $6.58 \times 10^{5}$ & $1.00 \times 10^{6}$ & 1.5 \\
\hline 37 & $1.54 \times 10^{5}$ & $8.28 \times 10^{4}$ & 0.5 & 87 & $4.25 \times 10^{5}$ & $5.24 \times 10^{5}$ & 1.2 \\
\hline 38 & $4.97 \times 10^{5}$ & $1.14 \times 10^{5}$ & 0.2 & 88 & $2.53 \times 10^{5}$ & $3.75 \times 10^{5}$ & 1.5 \\
\hline 39 & $4.97 \times 10^{5}$ & $4.41 \times 10^{5}$ & 0.9 & 89 & $3.76 \times 10^{5}$ & $1.99 \times 10^{5}$ & 0.5 \\
\hline 40 & $5.11 \times 10^{5}$ & $8.08 \times 10^{4}$ & 0.2 & 90 & $3.05 \times 10^{5}$ & $7.14 \times 10^{4}$ & 0.2 \\
\hline 41 & $7.17 \times 10^{4}$ & $1.04 \times 10^{5}$ & 1.5 & 91 & $2.89 \times 10^{5}$ & $1.94 \times 10^{5}$ & 0.7 \\
\hline 42 & $3.71 \times 10^{5}$ & $1.43 \times 10^{5}$ & 0.4 & 92 & $4.86 \times 10^{5}$ & $1.97 \times 10^{5}$ & 0.4 \\
\hline 43 & $3.13 \times 10^{5}$ & $1.91 \times 10^{5}$ & 0.6 & 93 & $1.92 \times 10^{5}$ & $4.97 \times 10^{5}$ & 2.6 \\
\hline 44 & $3.98 \times 10^{4}$ & $1.69 \times 10^{5}$ & 4.2 & 94 & $1.41 \times 10^{5}$ & $1.77 \times 10^{5}$ & 1.3 \\
\hline 45 & $2.90 \times 10^{5}$ & $5.15 \times 10^{5}$ & 1.8 & 95 & $7.80 \times 10^{5}$ & $1.50 \times 10^{6}$ & 1.9 \\
\hline 46 & $1.72 \times 10^{5}$ & $1.13 \times 10^{5}$ & 0.7 & & & & \\
\hline 47 & $2.26 \times 10^{5}$ & $2.68 \times 10^{5}$ & 1.2 & Dive & unt (maximum volv & ne) of each circle & spot was measured \\
\hline 48 & $6.03 \times 10^{5}$ & $4.01 \times 10^{5}$ & 0.7 & & & & \\
\hline
\end{tabular}

Table I. Continued.

Pixel count (maximum volume) of each circled spot was measured cyder. LIF, leukemia inhibitory factor. 


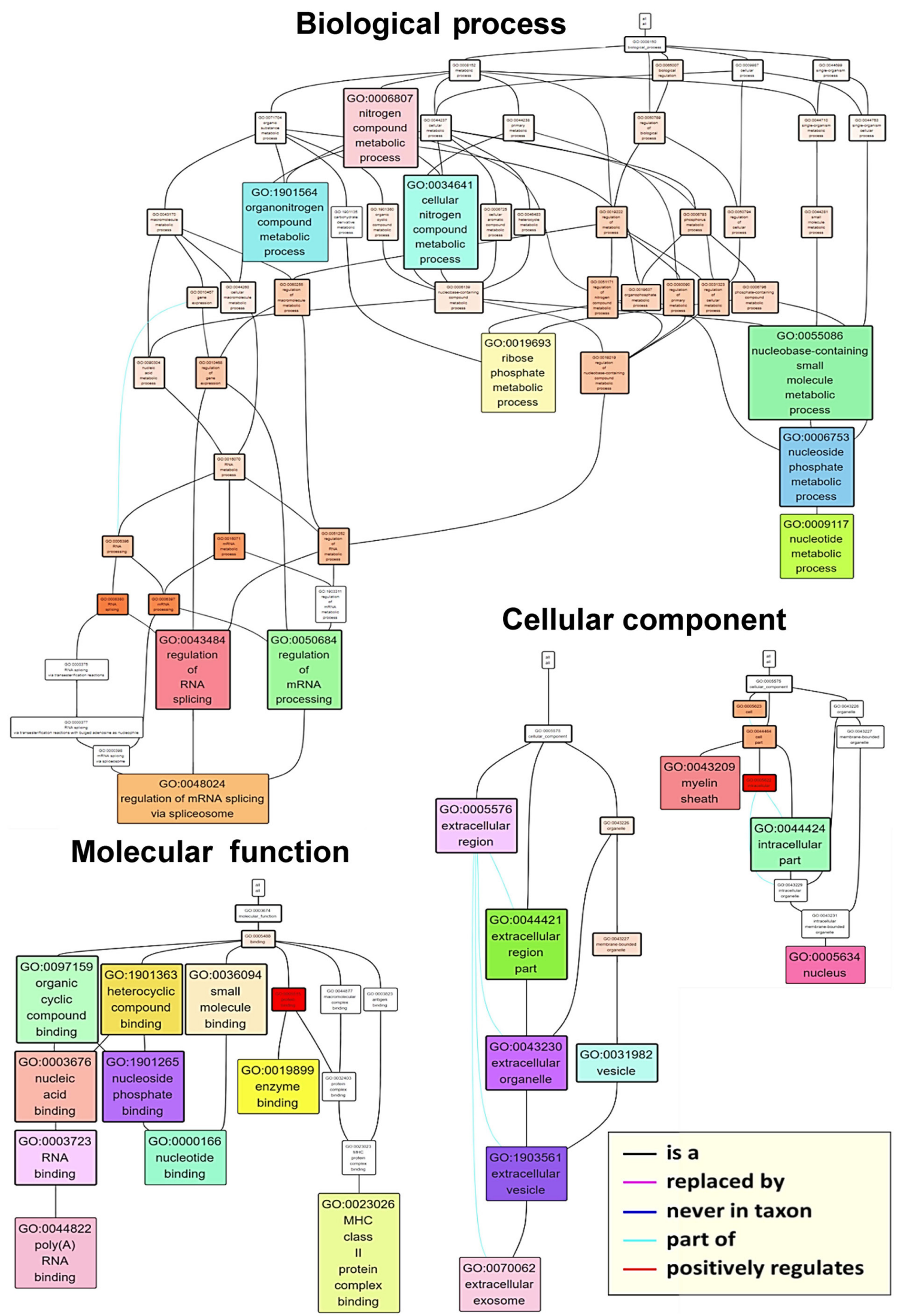

Figure 5. Hierarchical analysis of the top ten enriched terms in each GO category. The ten most significant GO terms of each category were subjected into hierarchical analysis using a web-based GO analytic tool, NaviGO. GO, Gene Ontology.

phosphorylated protein following LIF treatment was nuclear autoantigenic sperm protein (NASP; Table II). This histone H1 binding protein transports histones into the nuclei of dividing cells (24). NASP is phosphorylated following DNA damage (25), and its increased phosphorylation following LIF treatment may be associated with DNA repair during mESC 
Table II. Identification of phosphorylated proteins following leukemia inhibitory factor treatment via matrix-assisted laser desorption/ionization-time of flight mass spectrophotometry analysis.

\begin{tabular}{|c|c|c|c|c|c|}
\hline $\begin{array}{l}\text { Spot } \\
\text { no. }\end{array}$ & $\begin{array}{l}\text { Top ranked protein } \\
\text { name (species) }\end{array}$ & Accession no. & $\begin{array}{c}\text { Molecular } \\
\text { weight (Da) }\end{array}$ & $\begin{array}{l}\text { Isoelectric } \\
\text { point }\end{array}$ & $\begin{array}{c}\text { Ratio (LIF treatment/ } \\
\text { LIF deprivation) }\end{array}$ \\
\hline 2 & Nuclear autoantigenic sperm protein & NASP_MOUSE & 83902.7 & 4.4 & 8.8 \\
\hline 35 & Asparagine synthetase & ASNS_MOUSE & 64241.5 & 6.1 & 7.0 \\
\hline 44 & V-type proton ATPase subunit B, brain isoform & VATB2_MOUSE & 56514.9 & 5.6 & 4.2 \\
\hline 79 & Clathrin light chain A & CLCA_MOUSE & 25541.4 & 4.5 & 4.1 \\
\hline 16 & Serum albumin & ALBU_MOUSE & 68647.7 & 5.8 & 4.1 \\
\hline 23 & Nucleolin & NUCL_MOUSE & 76676.8 & 4.7 & 3.6 \\
\hline 66 & L-lactate dehydrogenase A chain & LDHA_MOUSE & 36475.2 & 7.6 & 3.5 \\
\hline 12 & Periodic tryptophan protein 1 homolog & PWP1_MOUSE & 55552.1 & 4.7 & 3.3 \\
\hline 19 & Nucleolin & NUCL_MOUSE & 76676.8 & 4.7 & 2.9 \\
\hline 93 & Thioredoxin domain-containing protein 12 & TXD12_MOUSE & 19036.5 & 5.1 & 2.6 \\
\hline 11 & Neurogenic locus notch homolog protein 1 & NOTC1_MOUSE & 271133.5 & 5.0 & 2.4 \\
\hline 14 & Heat shock cognate $71 \mathrm{kDa}$ protein & HSP7C_MOUSE & 70827.2 & 5.4 & 2.2 \\
\hline 17 & Sulfatase-modifying factor 1 & SUMF1_MOUSE & 40633.6 & 6.6 & 2.2 \\
\hline 58 & Eukaryotic translation initiation factor 3 subunit $\mathrm{H}$ & EIF3H_MOUSE & 39807.0 & 6.2 & 2.1 \\
\hline 64 & Transaldolase & TALDO_MOUSE & 37363.4 & 6.6 & 2.0 \\
\hline 21 & Elongation factor 2 & EF2_MOUSE & 95252.9 & 6.4 & 2.0 \\
\hline
\end{tabular}

LIF, leukemia inhibitory factor.

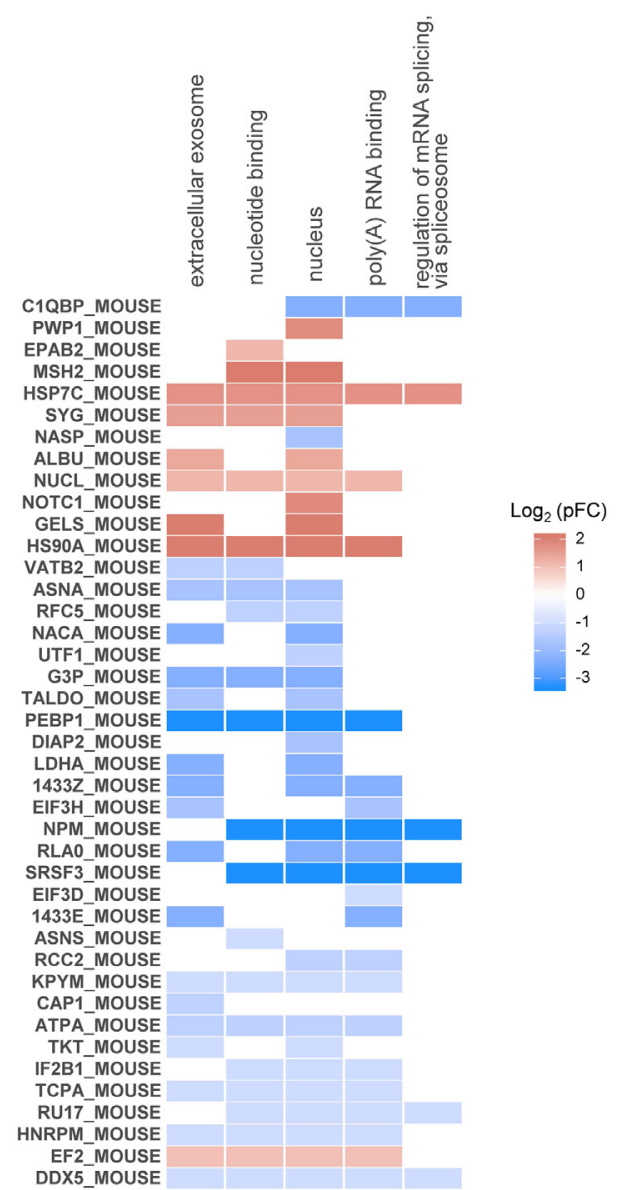

Figure 6. Association between representative terms in each GO category and protein members. A heatmap showing associations between terms and phosphorylation changes in protein members. Block colors indicates the log phosphorylation fold change with base 2 . Red, white and blue represent upregulation, no change and downregulation, respectively. GO, Gene Ontology. proliferation. There were two spots for NASP protein on the 2-D electrophoresis gel with the same molecular weight (138 kDa) and slightly different PI values (4.5 and 4.4), which differed from those reported in the NCBI database $(84 \mathrm{kDa}$ and 4.4). The phosphorylation of one spot was increased and the other was decreased by LIF stimulation. This suggested that different forms of NASP are differentially phosphorylated in response to LIF stimulation.

The second most significantly phosphorylated protein following LIF treatment was asparagine synthetase (AS). AS is a housekeeping enzyme that produces asparagine from aspartate and glutamine. In the majority of cells, AS regulates its activity in response to environmental asparagine levels (26). However, certain tumor cells have little or no AS activity and are reliant on exogenous asparagine (27). Therefore, tumor cells can be selectively killed by asparaginases. This approach has been exploited in the treatment of certain types of cancer, such as childhood acute lymphoblastic leukemia (28). To the best of our knowledge, whether AS is regulated by phosphorylation has not been reported.

Nucleolin (NUCL) is a multifunctional RNA binding protein involved in numerous cellular processes such as chromatin remodeling, ribosomal RNA synthesis, mRNA processing, ribosome assembly and nucleo-cytoplasmic transport (29). It has been demonstrated that NUCL serves an essential role in maintaining the self-renewal ability of ESCs due to its role in regulating cell cycle progression, proliferation and apoptosis prevention (30). The RNA-binding activity of NUCL is affected by phosphorylation (30). We found that different forms of NUCL are differentially phosphorylated in response to LIF stimulation.

The most significantly dephosphorylated protein following LIF treatment was the DNA mismatch repair protein MutS 
Table III. Identification of dephosphorylated proteins following leukemia inhibitory factor treatment via matrix-assisted laser desorption/ionization-time of flight mass spectrophotometry analysis.

\begin{tabular}{|c|c|c|c|c|c|}
\hline $\begin{array}{l}\text { Spot } \\
\text { no. }\end{array}$ & $\begin{array}{l}\text { Top ranked protein } \\
\text { name (species) }\end{array}$ & $\begin{array}{l}\text { Accession } \\
\text { no. }\end{array}$ & $\begin{array}{l}\text { Molecular } \\
\text { weight } \\
\text { (Da) }\end{array}$ & $\begin{array}{l}\text { Isoelectric } \\
\text { point }\end{array}$ & $\begin{array}{c}\text { Ratio } \\
\text { (LIF treatment/ } \\
\text { LIF deprivation) }\end{array}$ \\
\hline 83 & Nucleophosmin & NPM_MOUSE & 32539.8 & 4.60 & 0.1 \\
\hline 80 & $\begin{array}{l}\text { Complement component } 1 \mathrm{Q} \text { subcomponent-binding } \\
\text { protein, mitochondrial }\end{array}$ & C1QBP_MOUSE & 30993.5 & 4.80 & 0.1 \\
\hline 69 & Nascent polypeptide-associated complex subunit $\alpha$ & NACA_MOUSE & 23369.7 & 4.50 & 0.1 \\
\hline 22 & Elongation factor 2 & EF2_MOUSE & 95252.9 & 6.40 & 0.1 \\
\hline 7 & DNA mismatch repair protein Msh2 & MSH2_MOUSE & 104085.4 & 5.70 & 0.1 \\
\hline 40 & Adenylyl cyclase-associated protein 1 & CAP1_MOUSE & 51542.5 & 7.20 & 0.2 \\
\hline 20 & Nucleolin & NUCL_MOUSE & 76676.8 & 4.70 & 0.2 \\
\hline 24 & Nucleolin & NUCL_MOUSE & 76676.8 & 4.70 & 0.2 \\
\hline 38 & Protein RCC2 & RCC2_MOUSE & 55948.1 & 8.97 & 0.2 \\
\hline 65 & Glyceraldehyde-3-phosphate dehydrogenase & G3P_MOUSE & 35787.2 & 8.40 & 0.2 \\
\hline 90 & Serine/arginine-rich splicing factor 3 & SRSF3_MOUSE & 19317.9 & 11.60 & 0.2 \\
\hline 27 & Probable ATP-dependent RNA helicase DDX5 & DDX5_MOUSE & 69276.8 & 9.10 & 0.2 \\
\hline 8 & Gelsolin & GELS_MOUSE & 85888.1 & 5.80 & 0.2 \\
\hline 25 & Insulin-like growth factor 2 mRNA-binding protein 1 & IF2B1_MOUSE & 63411.2 & 9.30 & 0.3 \\
\hline 1 & Nuclear autoantigenic sperm protein & NASP_MOUSE & 83902.7 & 4.40 & 0.3 \\
\hline 77 & $60 \mathrm{~S}$ acidic ribosomal protein $\mathrm{P} 0$ & RLA0_MOUSE & 34194.8 & 5.90 & 0.3 \\
\hline 18 & Embryonic polyadenylate-binding protein 2 & EPAB2__MOUSE & 30244.1 & 6.40 & 0.3 \\
\hline 59 & Protein diaphanous homolog 2 & DIAP2_MOUSE & 124791.8 & 6.50 & 0.3 \\
\hline 81 & 14-3-3 protein $\varepsilon$ & 1433E_MOUSE & 29155.4 & 4.60 & 0.4 \\
\hline 56 & Replication factor $\mathrm{C}$ subunit 5 & RFC5_MOUSE & 38071.9 & 7.70 & 0.4 \\
\hline 82 & $14-3-3$ protein $\xi / \Delta$ & 1433Z_MOUSE & 27753.7 & 4.70 & 0.4 \\
\hline 42 & ATP synthase subunit $\alpha$, mitochondrial & ATPA_MOUSE & 59715.6 & 9.20 & 0.4 \\
\hline 92 & Nucleophosmin & NPM_MOUSE & 32539.8 & 4.60 & 0.4 \\
\hline 31 & Eukaryotic translation initiation factor 3 subunit D & EIF3D_MOUSE & 63948.4 & 5.80 & 0.4 \\
\hline 30 & U1 small nuclear ribonucleoprotein $70 \mathrm{kDa}$ & RU17_MOUSE & 51960.9 & 9.90 & 0.5 \\
\hline 49 & Undifferentiated embryonic cell transcription factor 1 & UTF1_MOUSE & 36385.8 & 10.10 & 0.5 \\
\hline 26 & Heterogeneous nuclear ribonucleoprotein M & HNRPM_MOUSE & 77597.4 & 8.80 & 0.5 \\
\hline 10 & Heat shock protein HSP $90-\alpha$ & HS90A_MOUSE & 84734.8 & 4.90 & 0.5 \\
\hline 15 & Glycyl-tRNA synthetase & SYG_M̄OUSE & 81825.7 & 6.20 & 0.5 \\
\hline 60 & ATPase Asna1 & ASNA_MOUSE & 38797.4 & 4.80 & 0.5 \\
\hline 3 & Spectrin $\alpha$ chain, brain & SPTA2_MOUSE & 284422.3 & 5.20 & 0.5 \\
\hline 29 & Transketolase & TKT_MOUSE & 67587.6 & 7.20 & 0.5 \\
\hline 89 & Phosphatidylethanolamine-binding protein 1 & PEBP1_MOUSE & 20817.3 & 5.20 & 0.5 \\
\hline 37 & Pyruvate kinase isozymes M1/M2 & KPYM_MOUSE & 57808.0 & 7.20 & 0.5 \\
\hline 32 & T-complex protein 1 subunit $\alpha$ & TCPA_MOUSE & 60410.7 & 5.80 & 0.5 \\
\hline
\end{tabular}

LIF, leukemia inhibitory factor.

homolog 2 (MSH2). MSH2 is commonly associated with hereditary non-polyposis colorectal cancer (31). MSH2 phosphorylation results in increased mismatch binding by the MutS $\alpha$ complex (32). The present study suggested that MSH2 dephosphorylation by LIF might be involved in the response of mESCs to genotoxic stress.

In addition, significantly differentially phosphorylated proteins following LIF treatment were analyzed for enrichment in GO biological processes, molecular functions and cellular components. Differentially phosphorylated proteins were enriched in 'poly(A) RNA' and 'nucleotide binding', 'localization to the nucleus' and 'extracellular exosomes' and 'regulation of mRNA splicing via the spliceosome'. A number of RNA binding proteins are dynamically regulated during reprogramming, suggesting an important role in mESC self-renewal (33). Previous studies have demonstrated that specific alternative splicing events can modulate transcriptional networks involved in pluripotency maintenance vs. differentiation $(34,35)$. These results suggest that the differentially phosphorylated 
Table IV. Top ten representative GO terms in each category.

A, Molecular function

\begin{tabular}{llrr}
\hline ID & & GO term & Adjusted P-value \\
\hline GO:0044822 & Poly(A) RNA binding & $9.606698 \times 10^{-13}$ & -2.836833 \\
GO:0003723 & RNA binding & $7.091495 \times 10^{-11}$ & -2.558409 \\
GO:0036094 & Small molecule binding & $5.858415 \times 10^{-9}$ & -2.041241 \\
GO:1901265 & Nucleoside phosphate binding & $4.889536 \times 10^{-8}$ & -1.705606 \\
GO:0000166 & Nucleotide binding & $4.889536 \times 10^{-8}$ & -1.705606 \\
GO:1901363 & Heterocyclic compound binding & $1.305847 \times 10^{-7}$ & -2.611165 \\
GO:0097159 & Organic cyclic compound binding & $1.902716 \times 10^{-7}$ & -2.611165 \\
GO:0019899 & Enzyme binding & $2.147613 \times 10^{-7}$ & -1.605910 \\
GO:0003676 & Nucleic acid binding & $2.339591 \times 10^{-7}$ & -2.116951 \\
GO:0023026 & MHC class II protein complex binding & $6.216308 \times 10^{-6}$ & 0.000000
\end{tabular}

B, Cellular component

\begin{tabular}{|c|c|c|c|}
\hline ID & GO term & Adjusted P-value & Z-score \\
\hline GO:0043209 & Myelin sheath & $2.648695 \times 10^{-11}$ & -0.904534 \\
\hline GO:0070062 & Extracellular exosome & $8.447870 \times 10^{-11}$ & -2.200000 \\
\hline GO:1903561 & Extracellular vesicle & $9.514470 \times 10^{-11}$ & -2.200000 \\
\hline GO:0043230 & Extracellular organelle & $1.005467 \times 10^{-10}$ & -2.200000 \\
\hline GO:0031988 & Membrane-bounded vesicle & $3.977979 \times 10^{-10}$ & -2.116951 \\
\hline GO:0031982 & Vesicle & $1.167650 \times 10^{-9}$ & -2.116951 \\
\hline GO:0005634 & Nucleus & $1.322581 \times 10^{-8}$ & -2.400980 \\
\hline GO:0044421 & Extracellular region part & $3.980441 \times 10^{-8}$ & -2.353394 \\
\hline GO:0044424 & Intracellular part & $8.712117 \times 10^{-8}$ & -3.015113 \\
\hline GO:0005576 & Extracellular region & $1.295624 \times 10^{-7}$ & -2.116951 \\
\hline
\end{tabular}

C, Biological process

\begin{tabular}{llrr}
\hline ID & & \multicolumn{1}{c}{ Term } & Adjusted P-value \\
\hline GO:1901564 & Organonitrogen compound metabolic process & $3.093931 \times 10^{-8}$ & -2.683282 \\
GO:0006807 & Nitrogen compound metabolic process & $7.391746 \times 10^{-7}$ & -3.181981 \\
GO:0048024 & Regulation of mRNA splicing, via spliceosome & $7.565866 \times 10^{-7}$ & -1.632993 \\
GO:0009117 & Nucleotide metabolic process & $7.969470 \times 10^{-7}$ & -1.507557 \\
GO:0006753 & Nucleoside phosphate metabolic process & $9.270259 \times 10^{-7}$ & -1.507557 \\
GO:0034641 & Cellular nitrogen compound metabolic process & $9.746239 \times 10^{-7}$ & -3.053290 \\
GO:0019693 & Ribose phosphate metabolic process & $1.119463 \times 10^{-6}$ & -1.897367 \\
GO:0055086 & Nucleobase-containing small molecule metabolic process & $1.923331 \times 10^{-6}$ & -1.507557 \\
GO:0050684 & Regulation of mRNA processing & $3.913029 \times 10^{-6}$ & -1.632993 \\
GO:0043484 & Regulation of RNA splicing & $5.405842 \times 10^{-6}$ & -1.632993 \\
\hline
\end{tabular}

GO, Gene Ontology.

proteins identified in the present study reflect mESC Funding

cellular functions.

\section{Acknowledgements}

Not applicable.
The present study was supported by a grant from the National Research Foundation (grant no. 2017M3A9B4065302) funded by the Ministry of Science and ICT in the Republic of Korea. 


\section{Availability of data and materials}

The datasets used and/or analyzed during the current study are available from the corresponding author on reasonable request.

\section{Authors' contributions}

HRS, HKK, SGK, HJL and HYK performed the experiments, collected and analyzed data and interpreted the results. MKH designed the experiments and wrote the manuscript. All authors read and approved the final manuscript.

\section{Ethics approval and consent to participate}

Not applicable.

\section{Patient consent for publication}

Not applicable.

\section{Competing interests}

The authors declare that they have no competing interests.

\section{References}

1. Martin GR: Isolation of a pluripotent cell line from early mouse embryos cultured in medium conditioned by teratocarcinoma stem cells. Proc Natl Acad Sci USA 78: 7634-7638, 1981.

2. Thomson JA, Itskovitz-Eldor J, Shapiro SS, Waknitz MA, Swiergiel JJ, Marshall VS and Jones JM: Embryonic stem cell lines derived from human blastocysts. Science 282: 1145-1147, 1998.

3. Aladjem MI, Spike BT, Rodewald LW, Hope TJ, Klemm M, Jaenisch R and Wahl GM: ES cells do not activate p53-dependent stress responses and undergo p53-independent apoptosis in response to DNA damage. Curr Biol 8: 145-155, 1998.

4. Takahashi K, Tanabe K, Ohnuki M, Narita M, Ichisaka T, Tomoda K and Yamanaka S: Induction of pluripotent stem cells from adult human fibroblasts by defined factors. Cell 131: 861-872, 2007.

5. Yu J, Vodyanik MA, Smuga-Otto K, Antosiewicz-Bourget J, Frane JL, Tian S, Nie J, Jonsdottir GA, Ruotti V, Stewart R, et al: Induced pluripotent stem cell lines derived from human somatic cells. Science 318: 1917-1920, 2007.

6. Rajarajan K, Engels MC and Wu SM: Reprogramming of mouse rat, pig, and human fibroblasts into iPS cells. Curr Protoc Mol Biol: Jan 1, 2012 (Epub ahead of print). doi: 10.1002/0471142727. $\mathrm{mb} 2315 \mathrm{~s} 97$.

7. Niwa H, Burdon T, Chambers I and Smith A: Self-renewal of pluripotent embryonic stem cells is mediated via activation of STAT3. Genes Dev 12: 2048-2060, 1998.

8. Ernst M, Oates A and Dunn AR: Gp130-mediated signal transduction in embryonic stem cells involves activation of Jak and Ras/mitogen-activated protein kinase pathways. J Biol Chem 271: 30136-30143, 1996.

9. Migone TS, Rodig S, Cacalano NA, Berg M, Schreiber RD and Leonard WJ: Functional cooperation of the interleukin-2 receptor beta chain and Jak1 in phosphatidylinositol 3-kinase recruitment and phosphorylation. Mol Cell Biol 18: 6416-6422, 1998.

10. Bechard M and Dalton S: Subcellular localization of glycogen synthase kinase 3beta controls embryonic stem cell self-renewal. Mol Cell Biol 29: 2092-2104, 2009.

11. Hermanns HM, Radtke S, Schaper F, Heinrich PC and Behrmann I: Non-redundant signal transduction of interleukin-6-type cytokines The adapter protein Shc is specifically recruited to rhe oncostatin M receptor. J Biol Chem 275: 40742-40748, 2000.

12. Huang W, Sherman BT and Lempicki RA: Systematic and integrative analysis of large gene lists using DAVID bioinformatics resources. Nat Protoc 4: 44-57, 2009.

13. Walter W, Sánchez-Cabo F and Ricote M: GOplot: An R package for visually combining expression data with functional analysis. Bioinformatics 31: 2912-2914, 2015.
14. Wei Q, Khan IK, Ding Z, Yerneni S and Kihara D: NaviGO: Interactive tool for visualization and functional similarity and coherence analysis with gene ontology. BMC Bioinformatics 18: $177,2017$.

15. Toumadje A, Kusumoto K, Parton A, Mericko P, Dowell L, Ma G, Chen L, Barnes DW and Sato JD: Pluripotent differentiation in vitro of murine ES-D3 embryonic stem cells. In Vitro Cell Dev Biol Anim 39: 449-453, 2003.

16. Meng GL, Zur Nieden NI, Liu SY, Cormier JT, Kallos MS and Rancourt DE: Properties of murine embryonic stem cells maintained on human foreskin fibroblasts without LIF. Mol Reprod Dev 75: 614-622, 2008.

17. Johansson $\mathrm{H}$ and Simonsson S: Core transcription factors, Oct4, Sox 2 and Nanog, individually form complexes with nucleophosmin (Npm1) to control embryonic stem (ES) cell fate determination. Aging (Albany NY) 2: 815-822, 2010.

18. Wu Y, Chen K, Xing G, Li L, Ma B, Hu Z, Duan L and Liu X: Phospholipid remodeling is critical for stem cell pluripotency by facilitating mesenchymal-to-epithelial transition. Sci Adv 5: eaax7525, 2019.

19. Xu Y, Zhao W, Olson SD, Prabhakara KS and Zhou X: Alternative splicing links histone modifications to stem cell fate decision. Genome Biol 19: 133, 2018.

20. Kwon YW, Ahn HS, Park JY, Yang HM, Cho HJ and Kim HS: Imprinted gene Zinc finger protein 127 is a novel regulator of master pluripotency transcription factor, Oct4. BMB Rep 51: 242-248, 2018.

21. Pyo JH, Jeon HJ, Park JS, Lee JS, Chung HY and Yoo MA: Drosophila PEBP1 inhibits intestinal stem cell aging via suppression of ERK pathway. Oncotarget 9: 17980-17993, 2018.

22. Ratnadiwakara M, Archer SK, Dent CI, Mozos IR, Beilharz TH, Knaupp AS, Nefzger CM, Polo JM and Anko ML: SRSF3 promotes pluripotency through Nanog mRNA export and coordination of the pluripotency gene expression program. Elife 7: e37419, 2018.

23. Li J, Sejas DP, Rani R, Koretsky T, Bagby GC and Pang Q: Nucleophosmin regulates cell cycle progression and stress response in hematopoietic stem/progenitor cells. J Biol Chem 281: 16536-16545, 2006.

24. Alekseev OM, Widgren EE, Richardson RT and O'Rand MG: Association of NASP with HSP90 in mouse spermatogenic cells: Stimulation of ATPase activity and transport of linker histones into nuclei. J Biol Chem 280: 2904-2911, 2005.

25. Alekseev OM, Bencic DC, Richardson RT, Widgren EE and O'Rand MG: Overexpression of the linker histone-binding protein tNASP affects progression through the cell cycle. J Biol Chem 278: 8846-8852, 2003

26. Lomelino CL, Andring JT, McKenna R and Kilberg MS: Asparagine synthetase: Function, structure, and role in disease. J Biol Chem 292: 19952-19958, 2017.

27. Gantt JS, Chiang CS, Hatfield GW and Arfin SM: Chinese hamster ovary cells resistant to beta-aspartylhydroxamate contain increased levels of asparagine synthetase. J Biol Chem 255: 4808-4813, 1980.

28. Ortega JA, Nesbit ME Jr, Donaldson MH, Hittle RE, Weiner J, Karon $M$ and Hammond D: L-Asparaginase, vincristine, and prednisone for induction of first remission in acute lymphocytic leukemia. Cancer Res 37: 535-540, 1977.

29. Zhang X, Xiao S, Rameau RD, Devany E, Nadeem Z, Caglar E, $\mathrm{Ng} \mathrm{K}$, Kleiman FE and Saxena A: Nucleolin phosphorylation regulates PARN deadenylase activity during cellular stress response. RNA Biol 15: 251-260, 2018.

30. Yang A, Shi G, Zhou C, Lu R, Li H, Sun L and Jin Y: Nucleolin maintains embryonic stem cell self-renewal by suppression of p53 protein-dependent pathway. J Biol Chem 286: 43370-43382, 2011.

31. Leach FS, Nicolaides NC, Papadopoulos N, Liu B, Jen J, Parsons R, Peltomäki P, Sistonen P, Aaltonen LA, Nyström-Lahti M, et al: Mutations of a mutS homolog in hereditary nonpolyposis colorectal cancer. Cell 75: 1215-1225, 1993.

32. Christmann M, Tomicic MT and Kaina B: Phosphorylation of mismatch repair proteins MSH2 and MSH6 affecting MutSalpha mismatch-binding activity. Nucleic Acids Res 30: 1959-1966, 2002.

33. Kwon SC, Yi H, Eichelbaum K, Föhr S, Fischer B, You KT, Castello A, Krijgsveld J, Hentze MW and Kim VN: The RNA-binding protein repertoire of embryonic stem cells. Nat Struct Mol Biol 20: 1122-1130, 2013.

34. Chen K, Dai X and Wu J: Alternative splicing: An important mechanism in stem cell biology. World J Stem Cells 7: 1-10, 2015.

35. Das S, Jena S and Levasseur DN: Alternative splicing produces Nanog protein variants with different capacities for self-renewal and pluripotency in embryonic stem cells. J Biol Chem 286: 42690-42703, 2011. 